\title{
THE INFLUENCE OF ORGANIZATIONAL JUSTICE ON THE PROFFESSIONAL BURNOUT
}

\author{
Marian NĂSTASE ${ }^{a}$, Nicolae BIBU ${ }^{b}$, Muhammad NUJEIDAT $^{c}$, Margareta Stela FLORESCU $^{d}$, \\ Denisa ABRUDAN ${ }^{e}$, Ileana V̆LLIMĂREANU (MIRCIOI) $f$ \\ ${ }^{a},{ }^{c},{ }^{d},{ }^{f}$ Bucharest University of Economic Studies, Romania \\ ${ }^{b},{ }^{e}$ West University Timișoara, Romania
}

DOI: $10.24818 / \mathrm{IMC} / 2020 / 04.22$

\begin{abstract}
As a general perspective, the burnout syndrome can be seen as an exhaustion state in which the person is doesn't succeed to cope with the challenges of his job, he doesn't realize anymore the value of his occupation and has posts serious doubts about its ability to work. The paper explores the mechanisms of burnout and ways of behavior for people whose profession involves a particular responsibility and frequent interactions with humans. This is an important issue as it appears more and more frequently in the modern age and leads to lower performance in the workplace, affecting relationships with others and the quality of performances and finally, the individual's life. The burnout syndrome is analyzed in connection to organizational justice that is based on the authority of the management to make decisions and reflects how the employees are treated in their workplace.
\end{abstract}

KEYWORDS: burnout syndrome, management, organizational justice, organizational performances.

\section{THE LITERATURE REVIEW}

Burnout syndrome includes chronic fatigue, susceptibility to diseases, feelings of failure, depression, helplessness and hopelessness, and negative attitudes towards work, service recipients, and organization (Pines, 2009). Maslach and Jackson (1981) defined professional burnout based on interviews that they conducted with professional therapists: Professional burnout is considered as a situation of emotional, physical, and mental exhaustion that comes in response to emotional demands in the workplace, which persists for long time. It has three main dimensions:

- Emotional Exhaustion, that is expressed by fatigue, lack of energy, overload sensation and emotional resources damping

- Depersonalization, which is expressed by negative attitudes or psychological and topical distancing from the problems of the patients through cynical and inhuman attitude and relationship to the patients as objects.

- Sensation of Lack of Self-Fulfillment (Personal Unaccomplishment), that is characterized by lack of feeling of personal achievement, development of sensation of failure at work, negative self-expression, decrease in the level of performance, withdrawal and feeling of lack of success (Maslach and Jackson, 1996).

The studies show that burnout is found in most service professions, and among professionals of treatment, when the work with people creates a heavy mental burden on the professional: the doctor, the nurse, the policeman, the teacher, the kindergarten teacher, the social worker, the manager and etc. (Malach-Fiennes, 2011; Schaibel \& Gecas, 2011; Poghosyan et al., 2010; Scharfeli et al., 2009; Kim \& Stoner, 2008). 
The stressors that cause burnout are not necessarily the result of regular contact with people. In the management professions, for example, the mental stress stems from the need to make important decisions in the absence of full information about the issue or time that is needed to achieve it (Malach-Fiennes, 2011). When the manager is in a situation of burnout, the situation is more problematic, because of the broad control and influence over the subordinates. The causes of burnout can be divided into two main groups: 1. Conduct and personal characteristics. 2. Factors that are related to the organization.

Society's changes influence the workplaces, work practices and the work environment. The stress at the workplace is recognized as a major health and safety occupational challenge. The concerns of such risks are rising due to the magnitude of the problem, the social costs of the stress at the workplace can be enormous (Hobfoll and Freedy, 1993). It is important to educate people in being aware to work and social pressures and to create a culture of performance, but with emphasize on people (Raducan et al. 2020).

The emergence of changes in the field of occupational health leads to a strict relationship with psychosocial factors and the present conditions of certain workplace situations which are directly related to the organization of tasks, their content and the type of tasks, but also the performance of the employees (Gil-Monte, 2012). In this sense, burnout can occur when there is an imbalance between work requirements and personal resources available to the employee (Bakker and Demerouti, 2013), his efforts to perform his duties and moreover, conflicts between values and employee motivations, but also between institutional missions and career guidance (Leiter, 2015).

The persistence of stress intensity experienced by each employee, along with successive attempts to treat them appropriately, can make the employee vulnerable and thus burnout syndrome (BS), a psychosocial phenomenon, can emerge as a chronic response to stress factors at the workplace. In conclusion, burnout syndrome is an advanced stage of stress at workplace and may cause total disability and/or permanent resumption of activity.

Burnout syndrome derives from the interaction of the individual with certain harmful psychosocial conditions at the workplace. The energy and the capacity of the employee may fall in time when the work environment does not provide enough resources. In the more advanced stages, burnout syndrome will appear as a state of physical, emotional and mental exhaustion and the recovery is very difficult. Also, burnout syndrome affects in an indirectly way the quality of the organizational activity, since people who suffer from this disease show reduced job performance and have a high potential of leaving the organization.

Sharma and Cooper (2017) define burnout as a progressive loss of idealism, energy and purposes, experienced by social, professional and non-professional operators, as a result of conditions in which they work.

Recently, a fourth symptom has been identified: loss of the control capacity compared to the professional activity, which leads to a reduction of the critical sense and therefore to an incorrect attribution of value in the working sphere. Burnout syndrome is characterized by specific state of minds, such as "anxiety, irritability, physical exhaustion, panic, restlessness, guilt, negativism, reduced self-esteem, empathy and listening skills), somatizations (migraine, sweats, insomnia, disorders), and behavioral reactions (absences or frequent delays, emotional detachment, reduced creativity”) (Hung Shuk Yu et al., 2018).

\section{EVALUATING THE BURNOUT}

There are several measurements built to examine the level of professional burnout, the prominent of them are the following.

The first is based on the questionnaire of Professional Burnout Evaluation is the Maslach Burnout Inventory (MBI), which was constructed by the researcher Christina Maslach. She considers the phenomenon of burnout according to three dimensions: mental exhaustion, psychological 
distancing, and non-fulfillment. Accordingly, the questionnaire examines these three dimensions and estimates the level of burnout accordingly. It should be noted that recently, professional literature has seen that the level of burnout should be measured according to one dimension which is formed of three dimensions and not three dimensions separately.

The second is MBI-ES, that is a version of the MBI includes an important modification of the original measure: it changed the word "recipient" into "student." In the education field, students are recipients of the educator. This change brought more consistency and clarity in the interpretation of the items. Several studies substantiated the reliability and validity of the MBI-ES (Maslach, Jackson and Leiter, 1996).

The third version of the MBI, the MBI-GS, involved more extensive changes of the original measure. This was due to researchers that used the MBIHSS scale, modified or unmodified, with occupational groups other than human service providers. These researchers reached to the conclusion that on the MBI-HSS subscales, not only did the scores of the groups they studied differ from norms established with human service providers, but the differentiation between the three subscales was not always maintained. The goal was to adapt and extend the MBI to occupations that did not have a primary focus on a service relationship.

Thus, the MBI-GS widened the definition of burnout so that it referred to the workplace in general. The MBI-GS has sixteen items and consist of three subscales that parallel the MBI-HSS: Cynicism (5 items), Exhaustion (5 items), and Professional Efficacy (6 items).

Another measurement, proposed by Pines and her colleagues (Pines, 2009), considers burnout as a situation of physical, mental, and emotional fatigue as a result of excessive preoccupation with mental and emotional phenomena and accordingly the questionnaire examines mental, emotional intellectual and physical measures and forms the level of burnout of the employee in accordance with these measures(Pines, 2009).

The Shirom-Melamed Burnout Measure (SMBM) (Shirom and Melamed, 2006) is an index is based on a theory (Hobbfoll and Freedy, 1993) which says that there are motives of the individual to preserve their material, physical and emotional resources. Accordingly, Melamed developed a measure to examine the level of burnout that relates only to the level of threat to these resources.

During the initial phase of burnout research, several researchers developed different scales to measure it. Some of them considered burnout as a unitary construct, while others considered it to be more multidimensional. These fundamentally different approaches happened because of differences in the methodological approach, concepts, assessment and in the content of the assessment of burnout (Jones, 2010).

Another approach is based on the Copenhagen Burnout Inventory (CBI), using three subdimensions: work-related burnout, personal burnout and client-related burnout. These parts of the questionnaire were designed to be used in various types of activities. The questions on personal burnout were conceived so that all human beings from every human activity could answer them.

The work-related burnout questions suppose that the respondent id doing a paid working an organizational setting. Finally, the client-related burnout questions embrace the term "client'. In our theoretical work we differentiate between working with customers, clients, and colleagues (Bowler, 2010).

The professional literature has reached the agreement that the Maslach measure is the most common measure to examine the level of burnout. It contains 47 statements which were subsequently reduced to 22 statements. In addition, the literature notes that the measure can be adapted to the various populations. Many researchers have found that the measure is reliable and valid (Cordes et al., 1997; Schaufeli et al., 2009). 


\section{CHARACTERISTICS OF THE ORGANIZATIONAL JUSTICE}

Organizational justice is the "complex of criteria according to which employees decide whether they have been properly treated in their work, and the ways in which these decisions affect other work-related variables” (Moorman 1991).

Steiner (1999) defined organizational justice as the employee's perception of inputs and outputs that he/she invests and accepts in the organization. Steiner and Bertolino (2006) defined organizational justice in a relative way according to which the employee examines himself/herself in relation to others, for example, the investment that he/she invests in his/her work, his/her age, his/her seniority and his/her education relative to same data of other employees compared to what the employee accepts and what the others accept. When the employee compares himself/herself to others, he/she examines a response in accordance with his/her sense of the relative process.

Accordingly, it can be assumed that the personal difference between an employee and another employee who is in most cases is a psychological basis of thought that constitutes a difference in the employees' perception of the essence of organizational justice. Rahim (2000) defines organizational justice as the perception of the culture and the organizational climate in the organization as they are perceived by the employees, both in the terms of procedural justice and in the terms of social relationships in the organization. Colquitt and his colleagues (2005) note that organizational justice refers to the perception of the results of the process of comparison based on the motives for organizational and managerial behavior within the organization.

The relationship between perception of injustice and occupational stress in connection to social support was rarely taken into consideration (Rousseau et al., 2009), even in front of a certain similarity between the construct of organizational trust and organizational support, and the conceptual overlap that can be seen between the theme of support and that of interactional justice.

Distributive justice was the first type of justice that was reflected in the results of the study or, more precisely, in the correctness of the results. Second type of justice, the procedural one, was distinguished by distributive justice because it reflects the correctness of the resulting procedures. Researchers also highlighted a third type of justice, the interactive justice, which addresses exchanges of interpersonal information about procedures and results. The distinction between types of justice helps to clarify the item that should put in relief, the appropriate theoretical rules to be applied, as well as the structure of the base (Rupp, 2011).

Colquitt et al. (2013) claim that employees quickly judge the extent of fairness and use all the information they have so that the extent of fairness of certain events represents the extent fairness of the entire organizational experience. It is therefore possible to examine the perception of organizational justice towards a particular event, such as teamwork, and it is possible to examine the degree of justice towards the organization and to obtain similar results.

The researchers refer to trust, commitment, perceived organizational support, and leadersubordinate relationships as indicators of the quality of the relationship that is created from social exchange, and found that the influence of organizational justice on good behavior such as organizational citizenship is moderated by these factors, but the influence of organizational justice on negative behavior, such as stealing from the organization is a direct influence. They also have found that organizational justice causes to people to feel good as injustice causes to people to feel bad (Colquitt et al., 2013).

Drawing on a review of 493 independent samples, Colquitt and colleagues found that significant relationships between organizational justice and both task performance and citizenship behavior were mediated by indicators of social exchange quality: trust, organizational commitment, perceived organizational support, and leader-member exchange). "With respect to affect, our results showed that justice-performance relationships were mediated by positive and negative affect, with the relevant affect dimension varying across justice and performance variables (Colquitt et al., 2013). 
Studies that engaged with staffs concluded that the extent to which employees think they are treated fairly should be considered because this affects their performance in the staff, absenteeism from teamwork, and staff effectiveness.

\section{RESEARCH METHODOLOGY}

We intended to show the connections between organizational justice and burnout by a research on the employees in the Arab public sector in Israel. The main research questions is the following: 1. How the perception of organizational justice affects the level of burnout of the employees in the Arab public sector in Israel? We have formulated the following hypothesis: H1 - There is a negative relation between organizational justice (OJ) perception and the level of professional burnout $(\mathrm{PB})$ in public organizations. As more organizational justice is perceived to exist within the organization, so the level of professional burnout is lower.

- H.1.1 - There are significant differences between categories of employees in terms of the level of burnout, so that employees with higher levels of education will report less burnout.

- H.1.2. - There are significant differences between categories of employees in terms of the level of burnout, so employees with many years of seniority will report higher levels of burnout.

- H.1.3. - There are significant differences between categories of employees in terms of the level of burnout, so managers will report higher level of burnout in comparison with other type of staff.

The research sample comprised a total of 389 participants that have completed valid questionnaire, all working in public organizations from North of Israel. The data was collected using a questionnaire including the following parts: Part A - Demographic background; Part B - Selfreporting questionnaire to the employee which includes the variable of organizational justice which is based on the measure (Neihoff and Moorman, 1993); Part C - Questionnaire of professional burnout examining from the questionnaire of Maslach et al. (1996).

The data was collected through distribution of the questionnaires in the field using pencil and paper based questionnaire distributed directly by the researcher to various random employees from public organizations in the northern part of Israel. The statistical processing of the gathered data was done using SPSS software.

\section{EXPLORING THE RESULTS}

The gender structure of respondents is $59,6 \%$ male respondents and $40,4 \%$ female respondents, indicating that men are representing most respondents. About the age of the respondents, the majority of respondents (44,5\%) are older than 46 years, indicating a relative aging of the public employees, since there are only $26,7 \%$ of employees between their 36 and 44 years old. A quite important age group is represented by young employees (28,8\%), between 26 and 25 years old, indicating a good trend of employing young people in public organizations from the researched area.

The situation is showing quite the same pattern from the "seniority" point of view. The group of respondents having a seniority longer than 10 years represent $64 \%$ of the total number of respondents, while those with a seniority less than 10 years represent $36 \%$, equally divided between those with a short seniority (less than 5 years) and those with an average seniority (between 6 and 10 years).

From the point of view of the" level of education" criteria the first important aspect is the fact that 317 respondents $(81,4 \%)$ obtained a higher education degree (bachelor, master, $\mathrm{PhD}$ ), with 170 people $(43,7 \%)$ with a master degree being the most important group. These results indicate that the professional quality of public employees is likely to be high. 
The sample of the research comprised $45 \% 175$ managers, that is $45 \%, 169$ junior managers (43,4\%) and $11.6 \% 45$ employees (11,6\%), fact that made this sample truly relevant for the managers of public administration. Only $11,6 \%$ of respondents were employees, although it has to be aimed for a more balanced sample. The main reason is that employees did not want to fill the questionnaire.

$\mathbf{H 1}$ - There is a negative relation between organizational justice $(\mathbf{O J})$ perception and the level of professional burnout (PB). As more organizational justice is perceived to exist within the organization, so the level of professional burnout is lower.

\section{Table 1. Pearson Correlations between organizational justice and level of professional burnout}

\begin{tabular}{clll}
\hline $\mathrm{N}$ & \multicolumn{2}{l}{ Organizational Professional } \\
389 & justice & burnout \\
\hline Organizational justice & 1 & $-415^{* *}$ \\
Professional burnout & $-414^{* *}$ & 1 \\
\hline
\end{tabular}

** Correlation is significant at the 0.01 level (1-tailed).

In line with the first study hypothesis, there was a significant and negative correlation between the Organizational justice and Professional burnout $(r=-.415)$. Thus, according with our results, approximatively $17 \%$ from the variation of the Professional burnout could be explained by the variation of the Organizational justice.

H.1.1 - There are significant differences between categories of employees in terms of the level of burnout, so that employees with higher levels of education will report less burnout.

Table 1.1 ANOVA results for the differences of the level of burnout between categories of employees

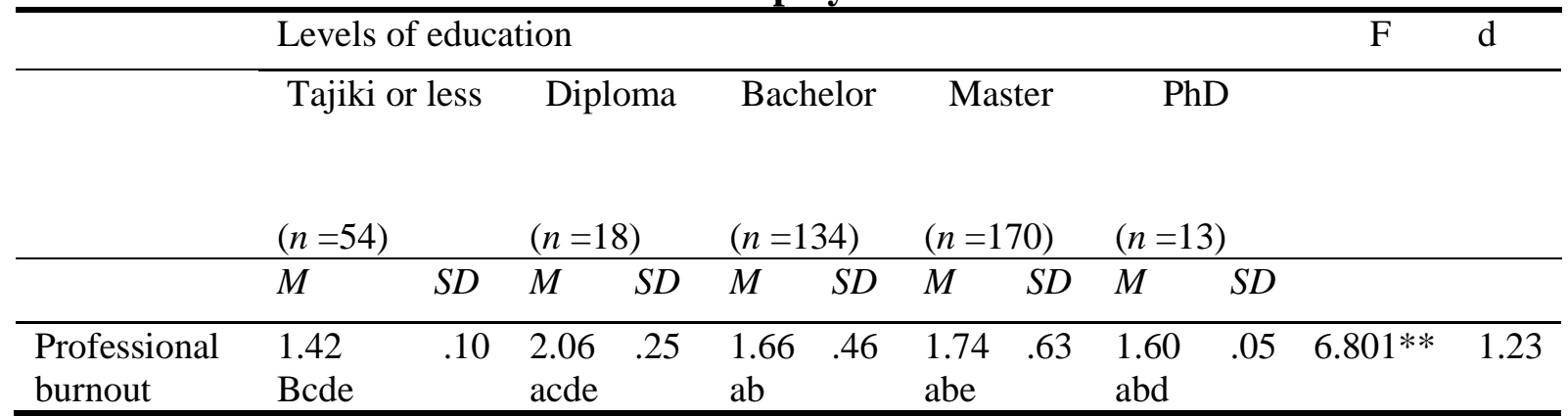

Note: ** $p<.001$. Difference regarding the four categories of employees: Tajiki or less (a), Diploma (b), Bachelor (c), Master (d) and PhD (e); according to post-hoc comparisons GamesHowell because the test of homogeneity is significant in all six cases.

The results of ANOVA (Table 1.1.) indicated significant differences $(F(18,724)=6.801, p<.001, d$ $=1.23$ ) between categories of employees in terms of the level of burnout. Employees with Tajiki or less education reported the lowest level of Professional burnout. This level is significant lower in comparison with all other four levels of Professional burnout reported in the cases of employees with diploma, bachelor, master or $\mathrm{PhD}$. Also, employees with $\mathrm{PhD}$ (the highest educational level) presented a level of Professional burnout significantly lower than similar levels observed in the cases of employees with diploma and master. Moreover, there are not significant differences between the levels of Professional burnout calculated in the case of employees with $\mathrm{PhD}$ and employees with bachelor. Thus, the results support only partial the hypothesis advanced. 
Table 1.2 ANOVA results for the differences of the level of burnout between categories of employees - levels of seniority

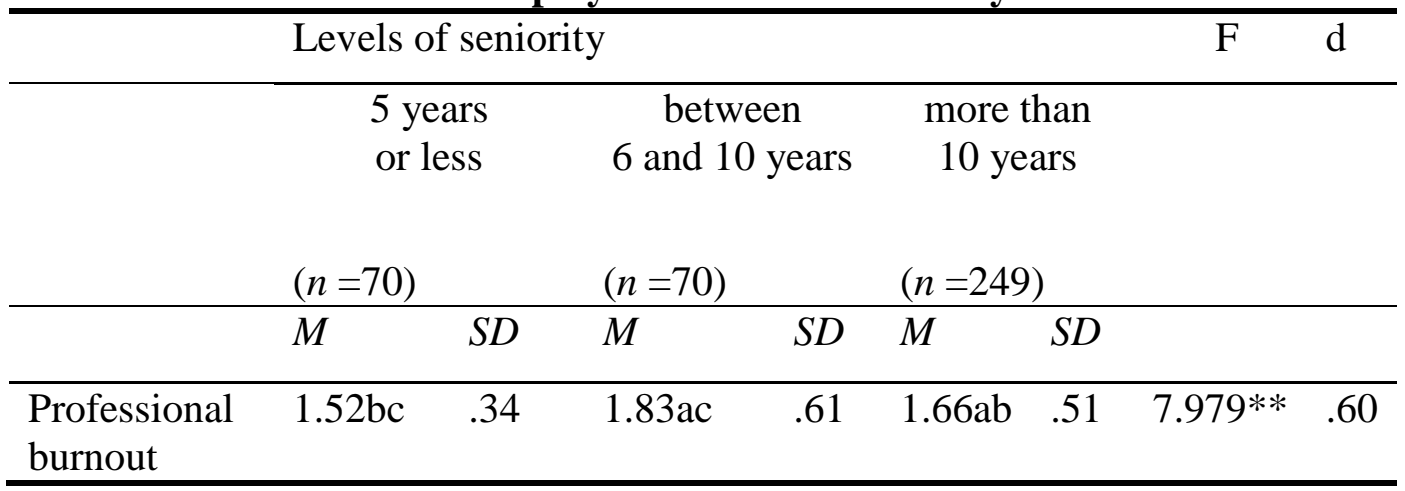

Note: $* * p<.001$. Difference regarding the four categories of employees: 5 years or less (a), between 6 and 10 years (b), and more than 10 years (c); according to post-hoc comparisons Games-Howell because the test of homogeneity is significant in all six cases.

The results of ANOVA (Table 1.2.) indicated significant differences $(F(7,447)=7.979, p<.001$, $d$ $=.60$ ) of the level of burnout between categories of employees with different years of seniority. It seems that employees with the highest level of seniority have lower level of burnout in comparison with employees that have between 6 and 10 years of seniority and, also, higher levels of burnout in comparison with employees that have less than 5 years of seniority. The hypothesis advanced the idea that employees with many years of seniority will report higher levels of burnout. Thus, the results support only partial the hypothesis advanced.

There are significant differences between categories of employees in terms of the level of burnout, so managers will report higher level of burnout in comparison with other type of staff.

Table 1.3 ANOVA results for the differences of the level of burnout between categories of employees - type of staff

\begin{tabular}{|c|c|c|c|c|c|}
\hline & Type of staf & & & $\mathrm{F}$ & $\mathrm{D}$ \\
\hline & employees & $\begin{array}{l}\text { junior } \\
\text { managers }\end{array}$ & managers & & \\
\hline & $(n=45)$ & $(n=169)$ & $(n=175)$ & & \\
\hline & $M \quad S D$ & $M \quad S D$ & $M \quad S D$ & & \\
\hline Professional burnout & $1.45 \mathrm{c} \quad .41$ & 1.63 c $\quad .35$ & $\begin{array}{ll}1.77 a b \quad .64\end{array}$ & 8.279 & .62 \\
\hline
\end{tabular}

Note: ${ }^{* *} p<.05$. Difference regarding the four categories of employees: employees (a), junior managers (b), and managers (c); according to post-hoc comparisons Games-Howell because the test of homogeneity is significant in all three cases.

The results of ANOVA (Table 1.3.) indicated significant differences $(F(4,237)=8.279, p<.001, d$ $=.62$ ) of the level of burnout between managers and other type of staff. It seems that managers reported the highest level of burnout. Thus, the results support the hypothesis advanced. Also, the results reported moderate effect size $(\mathrm{d}=.62)$.

We can extract from these results some interesting findings. Firstly, significant negative correlation resulted between the Organizational justice and Professional burnout, so as more organizational justice is perceived to exist within the organization, so the level of professional burnout is lower. 
Secondly, regarding the sub-hypotheses, the following resulted that supported partial or total the sub-hypotheses were: significant differences between categories of employees in terms of the level of burnout (Employees with Tajiki or less education reported the lowest level of Professional burnout. This level is significant lower in comparison with all other four levels of Professional burnout reported in the cases of employees with diploma, bachelor, master or $\mathrm{PhD}$. Also, employees with $\mathrm{PhD}$ (the highest educational level) presented a level of Professional burnout significantly lower than similar levels observed in the cases of employees with diploma and master. Moreover, there are not significant differences between the levels of Professional burnout calculated in the case of employees with $\mathrm{PhD}$ and employees with bachelor.). Also, that were significant differences of the level of burnout between categories of employees with different years of seniority (It seems that employees with the highest level of seniority have lower level of burnout in comparison with employees that have between 6 and 10 years of seniority and, also, higher levels of burnout in comparison with employees that have less than 5 years of seniority. The hypothesis advanced the idea that employees with many years of seniority will report higher levels of burnout.).

The results of ANOVA indicated another significant differences of the level of burnout between managers and other type of staff (It seems that managers reported the highest level of burnout.). The results of ANOVA indicated another significant differences of the level of burnout between employees from different type of authority (Thus, employees from relatively small authorities (between 5001 and 10000 inhabitants) reported the highest level of burnout. This level is significant different in comparison with very small authorities (between 1 and 5000 inhabitants) and very big authorities (more than 20000 inhabitants), but not significant different in comparison with mediumsized authorities (between 10001 and 20000 inhabitants).

\section{CONCLUSIONS}

Our study has validated that there is a negative correlation between organizational justice and professional burnout of public employees is validated and confirms several other research results. Managers of organizations, including public organizations need to increase through specific actions the level of fairness of organizational justice in their organizations because their positive effects on the professional burnout of employees.

These actions should be targeted to all employees, although with various specificities for various groups of employees. For example, the people with high education levels are more negatively affected by a lower level of organizational justice, so more prone to burnout. Since their percentage in the total number of public employees from the northern region of Israel in increasing, special attention should be given to these group of employees. The same happens with younger employees, having also a low level of seniority at work, under 5 years. A special attention should be given to managers, since they report the highest level of burnout due to organizational politics.

Professional burnout has negative impact on the individuals in organizations and on their contribution to the organization, reducing their performance at work. Therefore, reducing the level of organizational politics contributes directly to affect employees' burnout and job performance.

\section{ACKNOWLEDGMENT}

The authors acknowledge support from the project CNFIS-FDI-2020-0217 entitled "Developing the institutional capacity of Bucharest University of Economic Studies in the field of research excellence by supporting advanced research, visibility and innovation capacity in order to increase competitiveness in the European Research Area” (ECON_X). 


\section{REFERENCES}

Bowler, W., M. (2010). Organizational concern, prosocial values, or impression management? How supervisors attribute motives to organizational citizenship behavior. Journal of Applied Social Psychology, 40, 1450-1489.

Colquitt, J., A., Zapata-Phelan, C., P. \& Roberson, Q., M. (2005). Justice in teams: A review of fairness effects in collective contexts. In J. J. Martocchio (Ed.), Research in personnel and human resources management (Vol. 24, pp. 53-94). Oxford, UK: Elsevier.

Colquitt, J., A., Scott, B., A., Rodell, J., B., Long, D., M., Zapata, C., P., Conlon, D., E. et al. (2013). Justice at the millennium, a decade later: a meta-analytic test of social exchange and affect-based perspectives. Journal of Applied Psychology, 98(2), 199-236.

Cordes, C., L., Dougherty, T., W. \& Blum, M. (1997). Patterns of burnout among managers and professionals: a comparison of models. Journal of Organizational Behavior, 18, 685-701.

Gil-Monte, P., R. (2012). Validez factorial del Cuestionario para la Evaluación del Síndrome de Quemarse por el Trabajo (CESQT) en una muestra de médicos mexicanos. Univ Psychol, 9(1), 169-78.

Hobfoll, S., E. \& Freedy, J. (1993). Conservation of resources: A general stress theory applied to burnout. In W. B. Shaufeli, C. Maslach, Q Marek (Eds). Professional burnout: Recent development in theory and research. (pp.115-129). Washington, US: Taylor and Francis.

Hung Shuk Yu, M., Wong, L. M., Lam, K.K.S. (2018). The transition challenges faced by new graduate nurses in their first year of professional experience. GSTF J Nurs Health Care (JNHC), 5(1), 1-8.

Jones, D., A. (2010). Does serving the community also serve the company? Using organizational identification and social exchange theories to understand employee responses to a volunteerism programme. Journal of Occupational and Organizational Psychology, 83, 857-878.

Kim, H. \& Stoner, M. (2008). Burnout and turnover intention among social workers: Effect of role stress, job autonomy and social support. Administration in Social Work, 32(3), 5-25.

Leiter, M. (2015). Maslach Burnout Inventory Manual. $3^{\text {a }}$. ed. Palo Alto, CA: Consulting Psychologists Press.

Malach - Fiennes, A. (2011). Burnout at work - causes, results and coping ways. Moshav Ben Shemen: Mudan.

Maslach, C. \& Jackson, S. (1981). The Measurement of Experienced Burnout. Journal of Occupational Behavior, 2, 99-113.

Maslach, C., Jackson, S., E. \& Leiter, M., P. (1996). The Maslach Burnout Inventory (3rded.). Palo Alto, CA: Consulting Psychologists Press.

Moorman, R., H. (1991). Relationship between organizational justice and organizational citizenship behaviors: Do fairness perceptions influence employee citizenship? Journal of Applied Psychology, 76(6), 845-855.

Niehoff, B., P. \& Moorman, R., H. (1993). Justice as a mediator of the relationship between methods of monitoring and organizational citizenship behavior. Academy of Management Journal, 36(3), 527556.

Pines, A., M. (2009). Coping with burnout: a theoretical perspective and a corresponding measure. Chapter 18. In Antoniou, A. S., Cooper, C.L, Chrousos, G.P. (Ed). Handbook of managerial behavior and occupational health (pp. 252-263). Cheltelham, UK: Edward Elgar Publishing Limited.

Poghosyan, L., Clarke, S., P., Finlayson, M. \& Aiken, L., H. (2010). Nurse burnout and quality of care: Cross-national investigation in six countries. Research in Nursing \& Health, 33, 288-298.

Raducan, M., Vrabie, T., Colan, A., Colan, G., Cristache, N. \& Cristia, V. (2020). The influence of management style and socio-cultural factors on the education system in the European Union countries, Annals of the University Dunarea de Jos of Galati: Fascicle: I, Economics \& Applied Informatics, 26(1), 115-120.

Rahim, A., M. (2000). Empirical studies on managing conflict. International Journal of Conflict Management, 11(1), 5-8. 
Rousseau, V., Salek, S., Aubé, C. \& Morin, E., M. (2009). Distributive justice, procedural justice and psychological distress: the moderating effect of coworker support and work autonomy. Journal of Occupational Health Psychology, 14(3), 305-317. doi: 10.1037/a0015747.

Rupp, D., E. (2011). An employee-centered model of organizational justice and social responsibility. Organizational Psychology Review, 1, 72-94. doi: 10.1177/2041386610376255.

Schaufeli, W., B., Leiter, M., P. \& Maslach, C. (2009). Burnout: 35 years of research and practice. Career Development International, 14(3), 204-220.

Sharma, R., R. \& Cooper, C. (2017). Executive burnout: Eastern and Western concepts, models, and approaches for mitigation. London, UK: Emerald Press.

Shirom, A. \& Melamed, S. (2006). A comparison of the construct validity of two burnout measures in two groups of professionals. International Journal of Stress Management, 13(2), 176-200.

Steiner, D., D. (1999). Qu'est-ce qui est juste? Une introduction à la psychologie de la justice distributive et procédurale. In J. L. Beauvois, N. Dubois, Et W. Doise (Eds.), La Psychologie Sociale, Volume 4: La construction sociale de la personne (pp. 87-102). Grenoble, France: Presses Universitaires de Grenoble.

Steiner, D. D. \& Bertolino, M. (2006). The contributions of organizational justice theory to combating discrimination. Cahiers de l’Urmis, 10-11 Décembre, 1-11. 